\title{
ELECTROCHEMICAL BEHAVIOUR OF DIHYDROXYBENZENE ISOMERS AT GLASSY CARBON ELECTRODE IN DIFFERENT ELECTROLYTIC MEDIA
}

\author{
MD. TOUFIQUR RAHMAN, MD. UZZAL HOSSAIN AND M. Q. EHSAN* \\ Department of Chemistry, University of Dhaka, Dhaka-1000, Bangladesh
}

\begin{abstract}
Electrochemical behaviour of catechol, hydroquinone and resorcinol was investigated in $\mathrm{KCl}$, acetate buffer and phosphate buffer at glassy carbon electrod using cyclic voltammetry. The results imply that the glassy carbon electrode exhibited a synergistic and excellent electrocatalytic effect on the redox behaviors of the benzenediols. Catechol and hydroquinone show one pair of redox peaks in acetate and phosphate buffer but two pairs of redox peaks in $\mathrm{KCl}$. In all cases the redox process is quasireversible. Resorcinol behaves almost irreversibly in all three electrolytic media. Good linear relationships were obtained between the peak currents and the concentrations of benzenediols. The electrochemical process in all the isomers was controlled by diffusion process.
\end{abstract}

Key words: Catechol, Hydroquinone, Resorcinol, Glassy carbon electrode

\section{INTRODUCTION}

Catechol (CT), hydroquinone (HQ) and resorcinol (RC) are three dihydroxybenzene isomers, which are widely used in medicines, pesticides, cosmetics, tanning, flavoring agents, antioxidant, dye and photography chemicals (Wang et al. 2003). Due to their high toxicity and low degradability in the ecological environment, they are considered as environmental pollutants (Xie et al. 2006). During the manufacturing and application process of these compounds, some of them are inadvertently released into the environment to contaminate rivers and ground waters. Thus, it is easy for them to enter into the environments, and exists in industrial effluents and sanitary wastewater. Moreover, these isomers are often coexisting in environmental samples (Cui et al. 1999, Ding et al. 2005). It is necessary to develop simple and rapid analytical method for the determination of different types of dihydroxybenzene isomers. In developing methods it is urgent to know the behavior of each isomer.

Nowadays, electrochemical methods have attracted more and more attentions due to the advantages of fast response, cheap instrument, low cost, simple operation, time saving, high sensitivity, and excellent selectivity. Among all voltammetric techniques cyclic voltammetry however, has attracted attention to scientists in electrochemical

\footnotetext{
* Corresponding author: <mqehsan@yahoo.com>
} 
research, because, it can provide useful information about redox reaction in an easily interpretable form. In earlier communications the author reported electrochemical behavior of a few metal-ligand systems (Laizu et al. 2010, Akhter 2008, Islam 2009, Rahman 2011 and Hasan 2012). In this paper, the redox behaviour of CT, HQ and RC at glassy carbon electrode using cyclic voltametry in different electrolytic media are reported.

\section{MATERIALS AND METHODS}

The redox properties of dihydroxybenzene isomers, mechanism of reactions involving electro active species have been examined using cyclic voltammetry (CV). Chemicals used in the experiments were: (i) catechol (BDH), (ii) hydroquinone (BDH), (iii) resorcinol (BDH), (iv) $\mathrm{NaOH}$ pellets (A.R. grade), (v) potassium chloride (MERCK, Germany), (vi) potassium phosphate (monobasic) (MERCK, Germany), (vii) sodium acetate (MERCK, Germany) and (viii) acetic acid (Sigma-Aldrich Laborchemikaline, $\mathrm{GmbH}$ ). About $99.997 \%$ dry nitrogen (BOC, Bangladesh) was used for purging purpose. For cleaning and preparation of all solutions, deionized water was used.

This study was carried out using an Epsilon electroanalyser developed by Bioanalytical System, Inc. USA in a Pyrex glass micro cell with Teflon cap. Glassy carbon electrode was used as working electrode. $\mathrm{Ag} / \mathrm{AgCl}$ electrode was used as reference and Pt wire was used as counter electrode. An AGE (Velp Scientifica) magnetic stirrer with a teflon coated magnetic bar, a pH meter (ORION 2 STAR made by Thermo Electron Corporation) was employed for stirring and maintaining the $\mathrm{pH}$ value of the solutions, respectively.

\section{RESULTS AND DISCUSSION}

The redox behavior of all the isomers of dihydroxybenzene, catechol, hydroquinone and resorcinol have been studied using cyclic voltrammetry. The study was carried out at glassy carbon electrode (GCE) in $0.1 \mathrm{M} \mathrm{KCl}$, acetate buffer solution of $\mathrm{pH} 4.5$ and phosphate buffer solution of $\mathrm{pH} 7.0$ within the same potential window (from $-600 \mathrm{mV}$ to $+1200 \mathrm{mV}$ ) at various scan rates and various concentrations.

The cyclic voltammogram of $1 \mathrm{mM}$ catechol in $0.1 \mathrm{M} \mathrm{KCl}$ was taken within the potential window $-600 \mathrm{mV}$ to $+1200 \mathrm{mV}$. Fig. 1 depicts voltammograms of catechol and $\mathrm{KCl}$ solutions. There are two anodic peaks at $(+134 \mathrm{mV}$ and $+618 \mathrm{mV})$ and two cathodic peaks at $(+157.6 \mathrm{mV}$ and $-17.6 \mathrm{mV})$ respectively. The pair of peaks at $+134 \mathrm{mV}$ and $-17.6 \mathrm{mV}$ is very weak. 

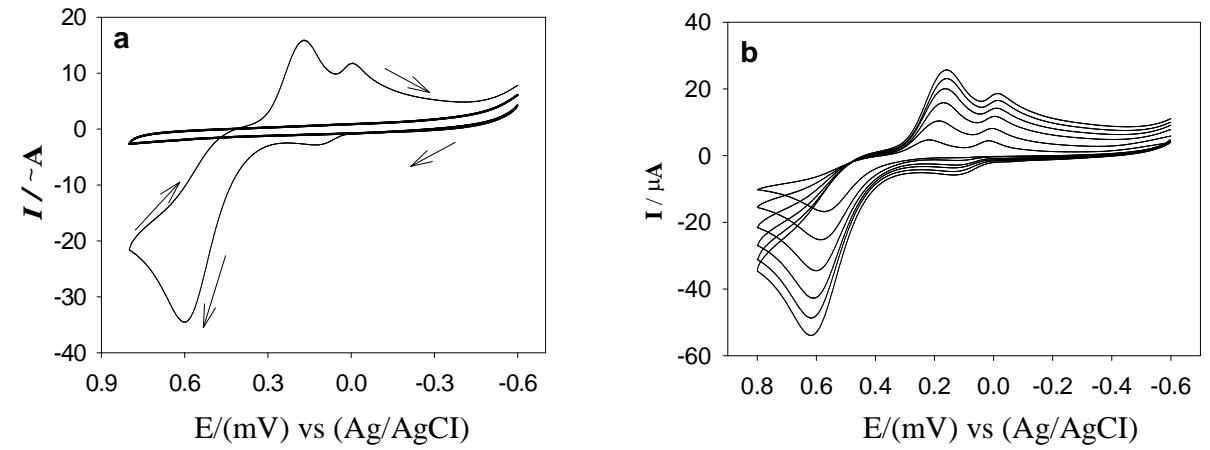

Fig. 1a. Cyclic voltammograms of $1 \mathrm{mM}$ catechol solution in $0.1 \mathrm{M} \mathrm{KCl}$ and the supporting electrolyte $0.1 \mathrm{M} \mathrm{KCl}$ at $100 \mathrm{mVs}^{-1}$ scan. b. CV of catechol solution at $20,50,100,150,200,250 \mathrm{mVs}^{-1}$ scan rate.

The redox reactions involve, can be explained in terms of electron transfer mechanism (Mascus et al. 1966) corresponding to the overall two one-electron transfer reaction for both anodic and cathodic process. The electrode reactions may be shown as,

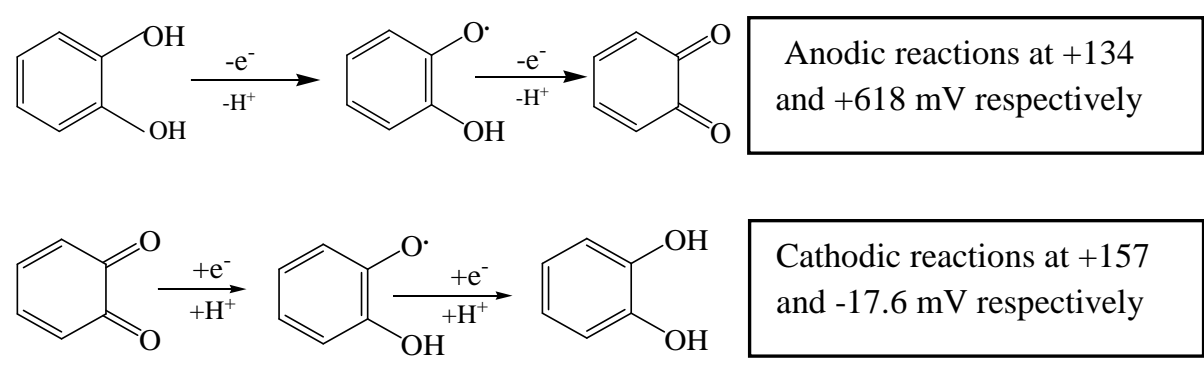

Table 1. Current-potential data, peak potential separation, peak current ratio of the voltammograms of $1 \mathrm{mM}$ catechol in $0.1 \mathrm{M} \mathrm{KCl}$ at different scan rates.

\begin{tabular}{|c|c|c|c|c|c|c|c|}
\hline $\begin{array}{c}v \\
\mathrm{Vs}^{-1}\end{array}$ & $v^{1 / 2}$ & $\begin{array}{l}\mathrm{Ep}_{\mathrm{a} 1} \\
\mathrm{~V}(+)\end{array}$ & $\begin{array}{l}E p_{c 1} \\
V(-)\end{array}$ & $\begin{array}{c}\mathrm{ip}_{\mathrm{a} 1} \\
\mu \mathrm{A}(-)\end{array}$ & $\begin{array}{c}\operatorname{ip}_{\mathrm{cl}} \\
\mu \mathrm{A}(+)\end{array}$ & $\begin{array}{c}\Delta \mathrm{E}_{1}= \\
\text { Epc1 } \sim \text { Epa1 (V) }\end{array}$ & $\mathrm{ip}_{\mathrm{a} 1 /} \mathrm{ip}_{\mathrm{c} 1}$ \\
\hline 0.020 & 0.141 & 0.155 & 0.009 & 2.12 & 5.65 & 0.164 & 0.375 \\
\hline 0.050 & 0.223 & 0.157 & 0.012 & 4.96 & 8.52 & 0.169 & 0.582 \\
\hline 0.100 & 0.316 & 0.162 & 0.015 & 6.97 & 10.72 & 0.177 & 0.650 \\
\hline 0.150 & 0.387 & 0.165 & 0.032 & 8.45 & 12.01 & 0.197 & 0.704 \\
\hline 0.200 & 0.447 & 0.170 & 0.035 & 11.33 & 14.14 & 0.205 & 0.801 \\
\hline 0.250 & 0.500 & 0.174 & 0.039 & 12.88 & 16.03 & 0.213 & 0.803 \\
\hline $\begin{array}{c}v \\
\mathrm{Vs}^{-1} \\
\end{array}$ & $v^{1 / 2}$ & $\begin{array}{l}\mathrm{Ep}_{\mathrm{a} 2} \\
\mathrm{~V}(+)\end{array}$ & $\begin{array}{l}\mathrm{Ep}_{\mathrm{c} 2} \\
\mathrm{~V}(+)\end{array}$ & $\begin{array}{c}\mathrm{ip}_{\mathrm{a} 2} \\
\mu \mathrm{A}(-)\end{array}$ & $\begin{array}{c}\mathrm{ip}_{\mathrm{c} 2} \\
\mu \mathrm{A}(+)\end{array}$ & $\begin{array}{c}\Delta \mathrm{E}_{2}= \\
\text { Epc2 Epa2 (V) }\end{array}$ & $\mathrm{ip}_{\mathrm{a} 2} / \mathrm{ip} \mathrm{p}_{\mathrm{c} 2}$ \\
\hline 0.020 & 0.141 & 0.570 & 0.210 & 16.10 & 3.89 & 0.360 & 4.138 \\
\hline 0.050 & 0.223 & 0.580 & 0.195 & 28.60 & 10.83 & 0.385 & 2.641 \\
\hline 0.100 & 0.316 & 0.598 & 0.178 & 37.89 & 18.45 & 0.420 & 2.054 \\
\hline 0.150 & 0.387 & 0.608 & 0.165 & 42.51 & 20.93 & 0.443 & 2.031 \\
\hline 0.200 & 0.447 & 0.615 & 0.160 & 49.23 & 24.19 & 0.455 & 2.035 \\
\hline 0.250 & 0.500 & 0.621 & 0.152 & 57.84 & 30.53 & 0.469 & 1.895 \\
\hline
\end{tabular}

$v=$ Scan rate $v^{1 / 2}=$ SQRT of scan rate; Epa = Anodic peak potential; Epc $=$ Cathodic peak potential; ipa $=$ Anodic peak current; ipc $=$ Cathodic peak current; $\Delta \mathrm{E}=$ Peak potential separation . 
A series of cyclic voltammograms of catechol in $\mathrm{KCl}$ at different scan rates are shown in Fig. 1b. The potential and current of all the CV for both pair of peaks are listed in Table 1. From the figure it is seen that for the cathodic peaks, the peak potentials gradually decreased and for the anodic peaks, the peak potentials gradually increased as the scan rate increased. But the increasing and decreasing rate of potential is very small. This behavior can be described by slower charge propagation, probably due to difference in solvation and or permeability (Wopshall and Shain 1967).

It is observed that the peak current increases with scan rate. In a slow voltage scan the diffusion layer grows much further from the electrode in comparison to a fast scan. Consequently, the flux to the electrode surface is considerably smaller at slow scan rates than it is at faster rates. As the current is proportional to the flux towards the electrode the magnitude of the current becomes lower at slow scan rates and higher at high scan rates. The general conclusion is that the redox system is diffusion controlled (Mascus et al. 1966).

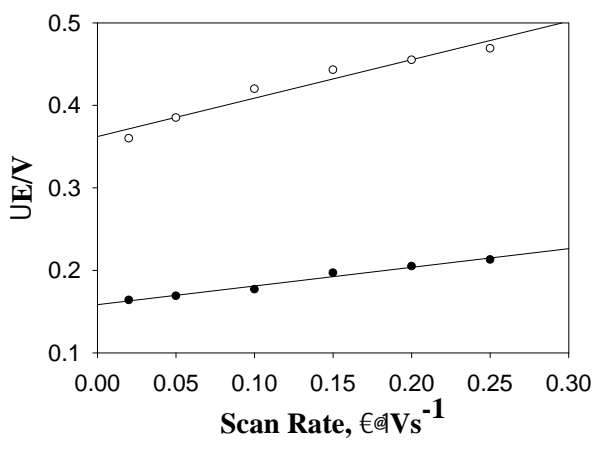

Fig. 2. Variation of peak potential separation against scan rate.

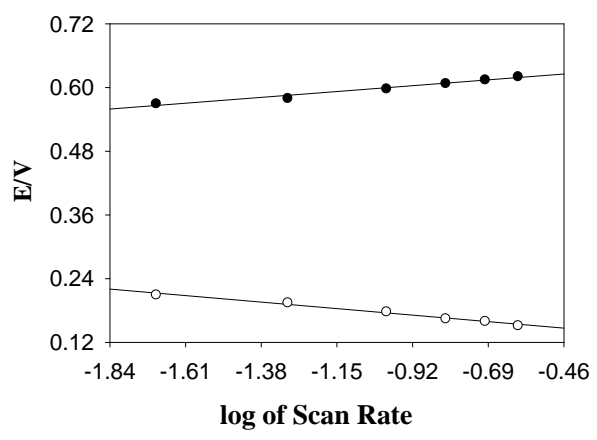

Fig. 4. Variation of peak potential against log of scan rate.

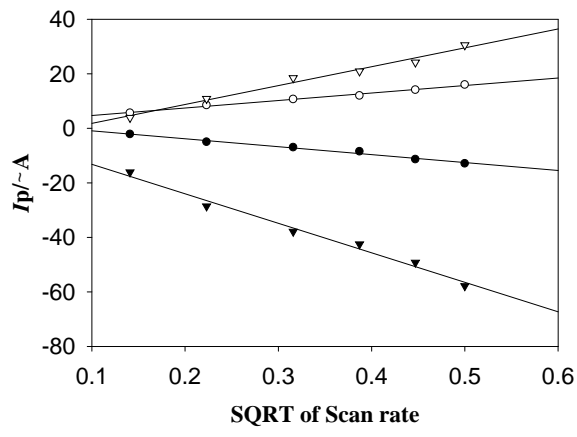

Fig. 3. Variation of peak current against SQRT of scan rate.

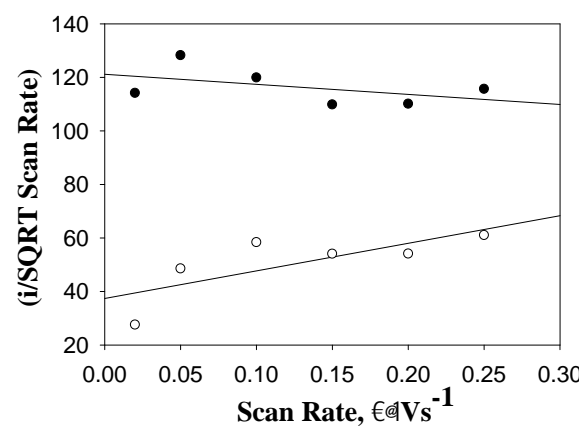

Fig. 5. Variation of peak current function against scan rate. 
From Fig. 2 it is clear that with increasing scan rate, the peak potential separation increases because the cathodic peak shifts towards negative potential and that of anodic towards positive potential. Here the cause is the effect of IR drop (Zhang and Anson 1992). Fig. 3 illustrates that with increasing SQRT of scan rate $\left(v^{1 / 2}\right)$, the peak currents increases, concluding that the process is adsorptive controlled (Bard and Faulkner 1980). The peak current ratio is found to be far from unity, which implies the system to be quasireversible. The slope of the potential vs log scan rate plot (Fig. 4) is not zero so, the process is not reversible. Peak current function vs scan rate plot (Fig. 5) shows the linear increment with scan rate, which implies that the electrochemical process under the investigation do not followed by any chemical process, i.e. it does not follow EC mechanism (Nicholson and Shain 1964, Golabi and Nimatollahi 2000).

The cyclic voltammograms of catechol of various concentrations $(1,2$ and $3 \mathrm{mM})$ in $0.1 \mathrm{M} \mathrm{KCl}$ at glassy carbon electrode at $50 \mathrm{mV} / \mathrm{sec}$ scan rate and the variation of peak current with concentration are shown in Fig 6. With the increase in concentration there is a gradual linear increase in peak current, which may be due to the presence of a large amount of electroactive species at higher concentration. The peak current increases with concentration also give the idea that the system may be diffusion controlled.
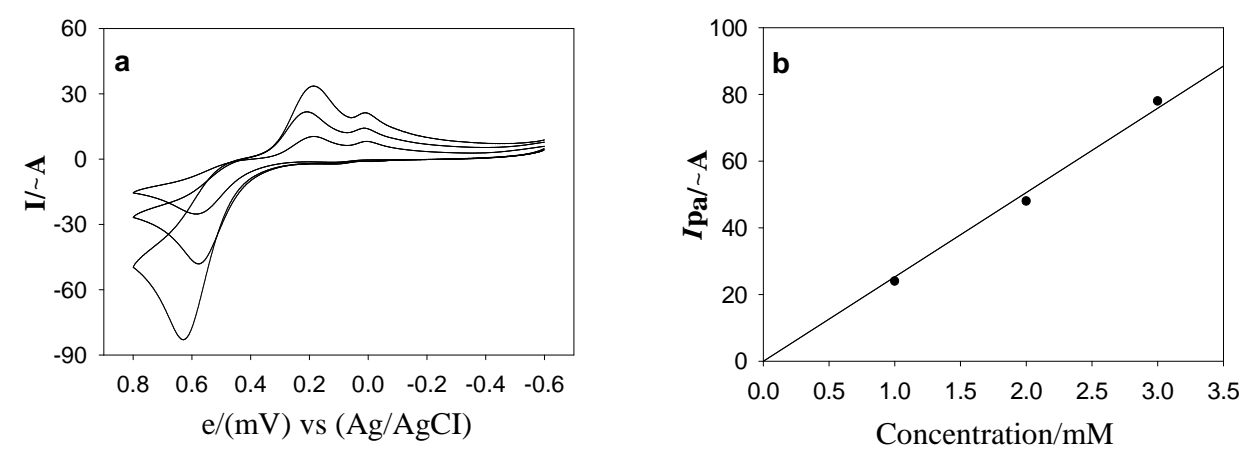

Fig. 6a. Cyclic voltammograms of 1, 2, $3 \mathrm{mM}$ catechol in $0.1 \mathrm{M} \mathrm{KCl}$ at GCE at $50 \mathrm{mVs}^{-1}$ scan rate. b. Variation of anodic peak current with concentration of catechol.

The cyclic voltammograms of $1 \mathrm{mM}$ catechol in acetate buffer and acetate buffer were taken within the same potential window and are shown in Fig. 7. Here the redox behavior of catechol has been modified. There is only one pair of anodic (at $+614 \mathrm{mV}$ ) and cathodic peaks $($ at $+80.0 \mathrm{mV}$ ). So, the redox process of catechol in acetate buffer involve one two-electron transfer reaction for both cathodic and anodic processes. 
The electrode reactions may be shown as,

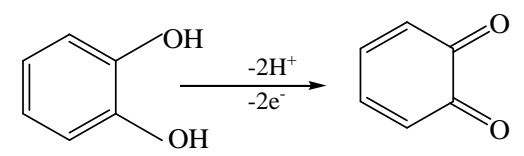

Anodic reaction at $+614 \mathrm{mV}$.<smiles></smiles>

Cathodic reaction at $+80 \mathrm{mV}$

The CVs at different scan rates are shown in Fig. 7b. The current-potential data, peak potential separation, peak current ratio of the voltammograms at different scan rates have been studied carefully. The change of peak separation with scan rate plot clearly indicate that with increasing scan rate, the peak potential separation increases because of the effect of IR drop. The increase of peak currents with increasing SQRT of scan rate $\left(\mathrm{v}^{1 / 2}\right)$, indicates that the process is adsorptive controlled. The peak current ratio was found to be very near to unity, which implies the system to be reversible.


Fig. 7a. Cyclic voltammograms of $1 \mathrm{mM}$ catechol solution in acetate buffer and the supporting electrolyte acetate buffer at $100 \mathrm{mVs}^{-1}$ scan. b. CV of catechol solution at $20,50,100,150,200,250 \mathrm{mV}^{\mathrm{s}-1}$ scan rate.

With the increase in concentration there is a gradual linear increase in peak current, which may be due to the presence of a large amount of electroactive species at higher concentration. The peak current increases with concentration also give the idea that the system may be diffusion controlled.

The redox behavior of catechol in the phosphate buffer is almost similar to that in the acetate buffer. There is only one pair of anodic and cathodic peaks but the peak positions are very much different. One pair of peaks implies that the redox process of catechol in phosphate buffer involve one two-electron transfer reactions for both cathodic and anodic processes and follows same mechanism. The probable reactions are as like that in the 
acetate buffer. The scan rate effect and concentration effect on the redox behavior of catechol in phosphate buffer follows similar trend and pattern.

The cyclic voltammogram of $1 \mathrm{mM}$ hydroquinone in $0.1 \mathrm{M} \mathrm{KCl}$ was taken within the potential window -600 to $+1200 \mathrm{mV}$. Fig. 8 a shows voltammograms of hydroquinone and $\mathrm{KCl}$. There are two anodic peaks at (-59 and $459 \mathrm{mV}$ ) and two cathodic peaks at (at 119 and $-128 \mathrm{mV}$ ). In this case the two pairs of cathodic and anodic peaks are very well defined.
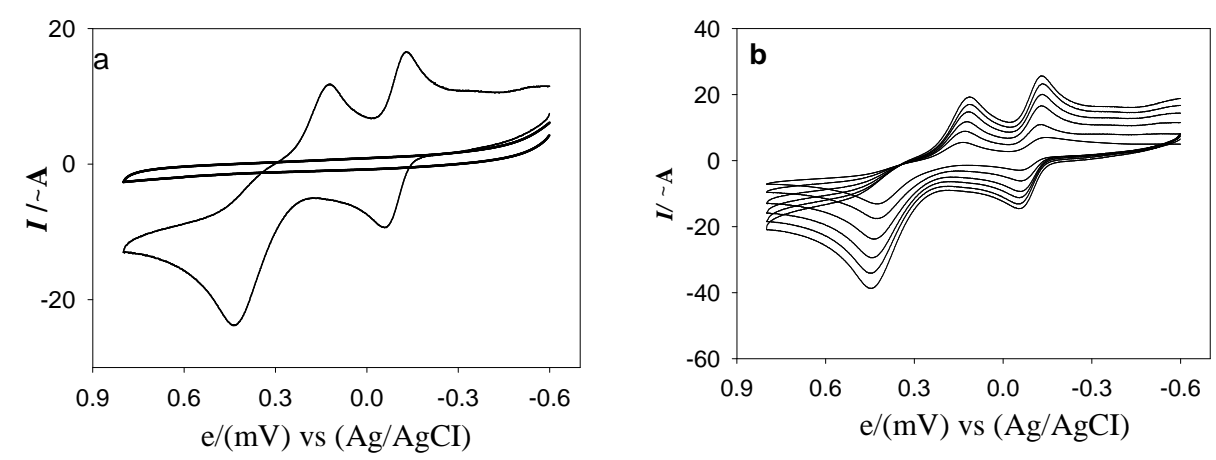

Fig. 8a. Cyclic voltammograms of $1 \mathrm{mM}$ hydroquinone solution in $0.1 \mathrm{M} \mathrm{KCl}$ and the supporting electrolyte $0.1 \mathrm{M} \mathrm{KCl}$ at $100 \mathrm{mVs}^{-1}$ scan rate. b. $\mathrm{CV}$ of hydroquinone at $20,50,100,150,200,250 \mathrm{mV}^{\mathrm{s}-1}$ scan rate.

The redox reactions involve in this system may be represented as two one-electron transfer reaction for both anodic and cathodic processes. Anode and cathode corresponds to the following reactions:<smiles></smiles>

Anodic reactions at -59 and +459 $\mathrm{mV}$ respectively

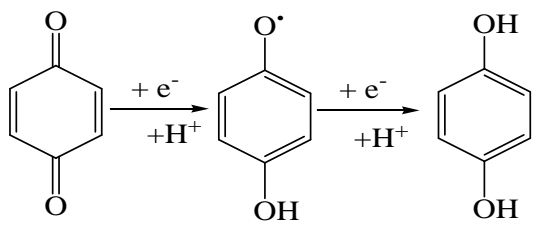

Cathodic reactions at +119 and $-128 \mathrm{mV}$ respectively

Cyclic voltammograms of hydroquinone in $\mathrm{KCl}$ at different scan rates are shown in Fig. 8b. The potential and current of all the CVs for both pair of peaks are listed in Table 2. Like that of catechol, the peak current increases with scan rate, the cathodic peak potentials are gradually decreased and the anodic peak potentials are gradually increased as the scan rate increased. This behavior indicates that the redox system is diffusion controlled. 
Table 2. Current-potential data, peak potential separation, peak current ratio of the voltammograms of $1 \mathrm{mM}$ hydroquinone in $0.1 \mathrm{M} \mathrm{KCl}$ at different scan rates.

\begin{tabular}{|c|c|c|c|c|c|c|c|}
\hline $\begin{array}{c}v \\
\mathrm{Vs}^{-1} \\
\end{array}$ & $v^{1 / 2}$ & $\begin{array}{l}\mathrm{Ep}_{\mathrm{a} 1} \\
\mathrm{~V}(-) \\
\end{array}$ & $\begin{array}{l}\mathrm{Ep}_{\mathrm{c} 1} \\
\mathrm{~V}(-) \\
\end{array}$ & $\begin{array}{c}\operatorname{ip}_{\mathrm{a} 1} \\
\mu \mathrm{A}(-)\end{array}$ & $\begin{array}{c}\operatorname{ip}_{\mathrm{c} 1} \\
\mu \mathrm{A}(+)\end{array}$ & $\begin{array}{c}\Delta \mathrm{E}_{1} \\
\text { Epc1 } \sim \operatorname{Epa} 1(\mathrm{~V})\end{array}$ & $\mathrm{ip}_{\mathrm{a} 1 /} / \mathrm{p}_{\mathrm{cl}}$ \\
\hline 0.020 & 0.141 & 0.054 & 0.121 & 5.65 & 6.43 & 0.067 & 0.878 \\
\hline 0.050 & 0.223 & 0.057 & 0.125 & 8.25 & 10.80 & 0.068 & 0.764 \\
\hline 0.100 & 0.316 & 0.060 & 0.130 & 11.29 & 16.73 & 0.070 & 0.675 \\
\hline 0.150 & 0.387 & 0.064 & 0.136 & 13.30 & 20.65 & 0.072 & 0.644 \\
\hline 0.200 & 0.447 & 0.070 & 0.140 & 15.10 & 22.9 & 0.070 & 0.659 \\
\hline 0.250 & 0.500 & 0.075 & 0.148 & 17.26 & 26.94 & 0.073 & 0.640 \\
\hline$v \underset{1}{v \mathrm{Vs}^{-}}$ & $v^{1 / 2}$ & $\begin{array}{l}\mathrm{Ep}_{\mathrm{a} 2} \\
\mathrm{~V}(+)\end{array}$ & $\begin{array}{l}\mathrm{Ep}_{\mathrm{c} 2} \\
\mathrm{~V}(-)\end{array}$ & $\begin{array}{c}\mathrm{ip}_{\mathrm{a} 2} \\
\mu \mathrm{A}(-)\end{array}$ & $\begin{array}{c}\mathrm{ip}_{\mathrm{c} 2} \\
\mu \mathrm{A}(+)\end{array}$ & $\begin{array}{c}\Delta \mathrm{E}_{2} \\
\text { Epc2 Epa2(V) }\end{array}$ & $\mathrm{ip}_{\mathrm{a} 2} / \mathrm{ip}_{\mathrm{c} 2}$ \\
\hline 0.020 & 0.141 & 0.422 & 0.132 & 13.10 & 6.89 & 0.554 & 1.901 \\
\hline 0.050 & 0.223 & 0.426 & 0.125 & 17.60 & 10.83 & 0.551 & 1.625 \\
\hline 0.100 & 0.316 & 0.434 & 0.128 & 23.89 & 16.45 & 0.562 & 1.452 \\
\hline 0.150 & 0.387 & 0.443 & 0.132 & 29.51 & 19.93 & 0.575 & 1.480 \\
\hline 0.200 & 0.447 & 0.447 & 0.134 & 34.23 & 23.19 & 0.581 & 1.476 \\
\hline 0.250 & 0.500 & 0.449 & 0.130 & 38.84 & 27.53 & 0.579 & 1.410 \\
\hline
\end{tabular}

$v=$ Scan rate $; v^{1 / 2}=$ SQRT of scan rate $;$ Epa $=$ Anodic peak potential $;$ Epc $=$ Cathodic peak potential; ipa $=$ Anodic peak current; ipc $=$ Cathodic peak current; $\Delta \mathrm{E}=$ Peak potential separation;

With the increasing SQRT of scan rate $\left(\mathrm{v}^{1 / 2}\right)$, the peak currents increases, giving the conclusion that the process is diffusion controlled and to some extent adsorptive controlled. Peak current function increases linearly with scan rate. Which implies that the electrochemical process under the investigation do not followed by any chemical process (Golabi and Nimatollahi 2000). The change of potential with log scan rate shows that for $1^{\text {st }}$ pair of peaks the slope is not zero but for the $2^{\text {nd }}$ pair of peaks it is almost zero. The peak current ratio for the 1 st pairs is less than unity and for $2^{\text {nd }}$ pair it is greater than unity. So, for the $1^{\text {st }}$ pair the process is nearly reversible and for the $2^{\text {nd }}$ pair the process is not reversible.

The effect of concentrations of hydroquinone on cyclic voltammograms found to be similar as that of catechol.

The cyclic voltammograms of $1 \mathrm{mM}$ hydroquinone and acetate buffer and the buffer solution are shown in Fig. 9. Here the redox behavior of hydroquinone has been modified. There is only one pair of anodic (at $+502.3 \mathrm{mV}$ ) and cathodic peaks (at -18.3 $\mathrm{mV})$. Which implies that the redox process of hydroquinone in acetate buffer involve one two-electron transfer reactions for both cathodic and anodic processes. 

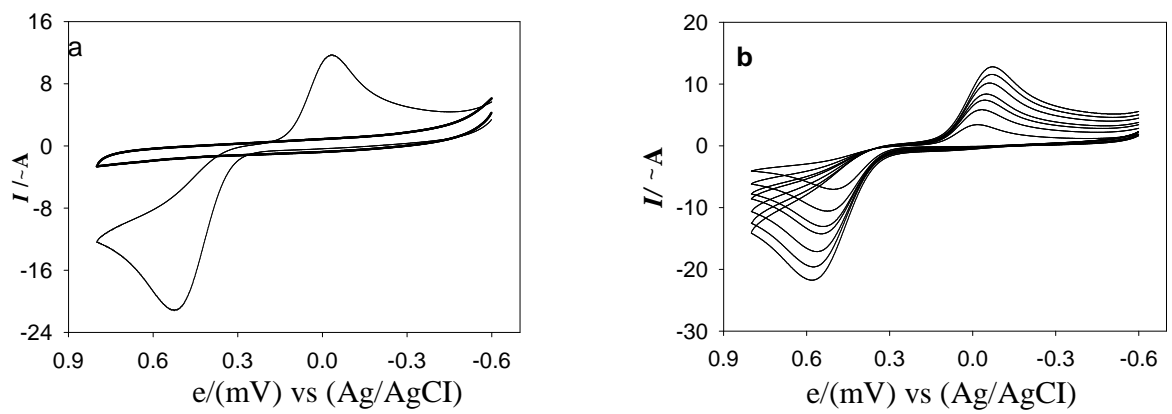

Fig. 9a. Cyclic voltammograms of $1 \mathrm{mM}$ hydroquinone solution in acetate buffer and supporting electrolyte acetate buffer at $100 \mathrm{mVs}^{-1}$ scan rate. b. $\mathrm{CV}$ of catechol solution at $20,50,100,150,200,250 \mathrm{mV}^{\mathrm{s}-1}$ scan rate.

Two-electron transfer reactions at anode and cathode may be represented as follows:<smiles>Oc1ccc(O)cc1</smiles><smiles>C[I+]#CC1C=CC(=O)C=C1</smiles>

Anodic reaction at $+502.3 \mathrm{mV}$<smiles>O=C1C=CC(=O)C=C1</smiles><smiles>Oc1ccc(O)cc1</smiles>

Cathodic reaction at $-18.3 \mathrm{mV}$

A series of cyclic voltammograms of $1 \mathrm{mM}$ hydroquinone in acetate buffer at different scan rates are shown in Fig. 9b. The pattern of change of peak currents and peak positions with scan rate are similar to that in $\mathrm{KCl}$ solution. It is observed that the peak current increases with scan rate, indicating that the redox system is diffusion controlled. The peak current ratio is found to be greater than unity, which implies the system may be quasi-reversible.

The cyclic voltammograms of hydroquinone various concentrations in acetate buffer solution of were studied at $50 \mathrm{mV} / \mathrm{sec}$ scan rate. With the increase in concentration there is a gradual linear increase in peak current suggesting the diffusion controlled process.

The redox behavior of hydroquinone in the phosphate buffer is almost similar to that in the acetate buffer. There is only one pair of anodic and cathodic peaks but the peak positions are very much different. One pair of peaks implies that the redox process of hydroquinone in phosphate buffer involve one two-electron transfer reaction for both cathodic and anodic processes and follows same mechanism. The probable reaction would be as like in the acetate buffer. 
The cyclic voltammograms of $1 \mathrm{mM}$ resorcinol in $0.1 \mathrm{M} \mathrm{KCl}$ and $\mathrm{KCl}$ are shown in Fig. 10a. There is one anodic peak at $(+908 \mathrm{mV})$ and one very weak cathodic peak at about $(-200$ $\mathrm{mV})$. The process is almost irreversible.
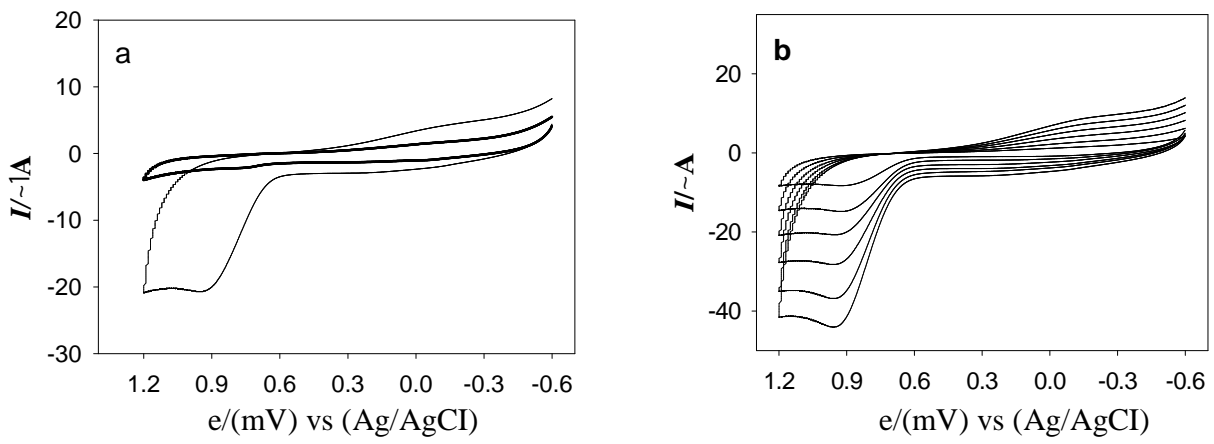

Fig. 10a. Cyclic voltammograms of $1 \mathrm{mM}$ resorcinol solution in $0.1 \mathrm{M} \mathrm{KCl}$ and the supporting electrolyte $0.1 \mathrm{M} \mathrm{KCl}$ at $100 \mathrm{mVs}^{-1}$ scan rate. b. $\mathrm{CV}$ of resorcinol solution at $20,50,100,150,200,250 \mathrm{mV}^{\mathrm{s}-1}$ scan rate.

The reactions involve in the redox process can be explained in terms of electron transfer mechanism, corresponding to the overall one two-electron transfer reaction such as:<smiles>O=C1C=CCC(=O)C1</smiles>

Anodic reaction at $+908 \mathrm{mV}$

A series of cyclic voltammograms of $1 \mathrm{mM}$ resorcinol in $\mathrm{KCl}$ at different scan rates were taken and are shown in Fig. 10b. The potential and current of all the CV are listed in Table 3. From the figure it is seen that, the peak potentials are almost same as the scan rate increased. This behavior can be described by extremely slower charge propagation, probably due to difference in solvation and or permeability.

Table 3. Current-potential data, peak potential separation, peak current ratio of the voltammograms of $1 \mathrm{mM}$ resorcinol in $0.1 \mathrm{M} \mathrm{KCl}$ at different scan rates.

\begin{tabular}{cccccccc}
\hline $\begin{array}{c}v \\
\mathrm{Vs}^{-1}\end{array}$ & $v^{1 / 2}$ & $\begin{array}{c}\mathrm{E}_{\mathrm{pa}} \\
\mathrm{V}(+)\end{array}$ & $\begin{array}{c}\mathrm{E}_{\mathrm{pc}} \\
\mathrm{V}(+)\end{array}$ & $\begin{array}{c}\mathrm{i}_{\mathrm{pa}} \\
\mu \mathrm{A}(-)\end{array}$ & $\begin{array}{c}\mathrm{i}_{\mathrm{pc}} \\
\mu \mathrm{A}(+)\end{array}$ & $\begin{array}{c}\Delta \mathrm{E}= \\
\mathrm{E}_{\mathrm{pc}} \sim \mathrm{E}_{\mathrm{pa}}(\mathrm{V})\end{array}$ & $\mathrm{i}_{\mathrm{pa}} / \mathrm{i}_{\mathrm{pc}}$ \\
\hline 0.020 & 0.141 & 0.882 & 0.255 & 9.10 & 0.51 & 0.627 & 17.843 \\
0.050 & 0.223 & 0.890 & 0.249 & 16.60 & 1.03 & 0.641 & 16.116 \\
0.100 & 0.316 & 0.910 & 0.242 & 21.89 & 1.45 & 0.668 & 15.096 \\
0.150 & 0.387 & 0.915 & 0.240 & 30.51 & 2.53 & 0.675 & 12.059 \\
0.200 & 0.447 & 0.922 & 0.238 & 38.23 & 3.59 & 0.684 & 10.649 \\
0.250 & 0.500 & 0.932 & 0.235 & 48.84 & 5.63 & 0.697 & 8.675 \\
\hline
\end{tabular}

$v=$ Scan rate $v^{1 / 2}=\mathrm{SQRT}$ of scan rate $\mathrm{E}_{\mathrm{pa}}=$ Anodic peak potential $; \mathrm{E}_{\mathrm{pc}}=$ Cathodic peak potential; $\mathrm{i}_{\mathrm{pa}}=$ Anodic peak current; $\mathrm{i}_{\mathrm{pc}}=$ Cathodic peak current $\Delta \mathrm{E}=$ Peak potential separation. 
It was also observed that the peak current increased with scan rate. The flux to the electrode surface was considerably smaller at slow scan rates than it is at faster rates. As the current is proportional to the flux towards the electrode the magnitude of the current becomes lower at slow scan rates and higher at high scan rates. The general conclusion is that the redox system is diffusion-controlled. The peak current ratio was found to be greater than unity, which implies the system may be irreversible.

The cyclic voltammograms of resorcinol of various concentrations (1,2 and $3 \mathrm{mM})$ in $0.1 \mathrm{M} \mathrm{KCl}$ solution at glassy carbon electrode at $50 \mathrm{mV} / \mathrm{sec}$ scan rate. The peak current increases with the concentration also give the idea that the system may be diffusion controlled.

The cyclic voltammograms of $1 \mathrm{mM}$ resorcinol in acetate buffer and phosphate buffer were studied in the similar way. The redox process in resorcinol in both the buffer systems ware almost identical to that in $\mathrm{KCl}$ solution.

\section{CONCLUSION}

Both catechol and hydroquinone gave two anodic and two cathodic peaks in $\mathrm{KCl}$ solution. This indicates that the redox process involves two one-electron transfer reactions at glassy carbon electrode. On the other hand in acetate buffer and in phosphate buffer catechol and hydroquinone gave one anodic and one cathodic peak indicating that in these supporting electrolytes the redox process involves one two-electron transfer reaction in both anode and cathod. Both catechol and hydroquinone showed quasi-reversible behavior at glassy carbon electrode. Resorcinol gave only one sharp anodic peak and a very weak cathodic peak in all media except slight difference in peak potential. This indicates that in these supporting electrolytes each of the redox reaction involves two electron transfers. The peak current ratios were found to be greater than unity.

\section{REFERENCES}

Akhter, H. M. N., M. M. Jamal, A. A. Shaikh and M. Q. Ehsan. 2008. Cyclic voltammetric study of the interaction of copper with glutamic acid in solution. J. Saudi Chem. Soc. 12(2): 177-182.

Bard, A. J. and L.R. Faulkner. 1980. Electrochemical Methods Fundamentals and Application. pp. 199-236, John Wiley and Sons Inc., New York.

Cui, H., C. He and G. Zhao. 1999. Determination of polyphenols by high-performance liquid chromatography with inhibited chemiluminescence detection. J. Chromatogr. A. 855 : 171.

Ding, Y., W. Liu, Q. Wu and X. Wang. 2005. Direct simultaneous determination of dihydroxybenzene isomers at C-nanotube-modified electrodes by derivative voltammetry. J. Electroanal. Chem. 575: 275.

Golabi, S. M. and D. Nimatollahi. 2000. Investigation of the electro-methoxylation reaction: Part 1. Electrochemical study of 4-tert-butylcatechol and 3,4-dihydroxybenzaldehyde in methanol.

J. Electrocanal. Chem. 481: 208. 
Akhter, N., A. A. Shaikh and M. Q. Ehsan. 2008. Cyclic Voltammetric Study of The Redox Behaviour of $\mathrm{Fe}(\mathrm{II}), \mathrm{Fe}(\mathrm{III})$ Systems Forming During The Oxidation of $\mathrm{Fe}$ (II) Complexes With Saccharine And With Saccharin And 1,10-Phenanthroline. Russian J. Electrochem. 44(12): 1504-1509.

Hasan, M.M., M. E. Hossain, M. A. Mamun and M. Q. Ehsan. 2012. Study of Redox Behaviour of $\mathrm{Cd}(\mathrm{II})$ and Interaction of $\mathrm{Cd}(\mathrm{II})$ with Proline in the Aqueous Medium Using Cyclic Voltammetry. Journal of Saudi Chemical Society 16: 145-151.

Islam, G. J., H. M. Naseem Akhter, M. A. Mamun and M. Q. Ehsan. 2009. Investigations on the Redox Behavior of Manganese(II)-Saccharin and Manganese(II)-Saccharin-1,10Phenanthroline Complex. J. Saudi Chem. Soc. 13: 177-143.

Laizu, M., H. M. Naseem Akhter, M. A. Mamun, M. A. Jabbar and M. Q. Ehsan. 2010. Cyclic Voltammetric Study on the Effect of the Introduction of Secondary Ligands on the Behaviour of the Copper-Saccharin Complex. J. Natn. Sci Foundation Sri Lanka 38(2): 91-99.

Mascus, M., F. Parient, Q. Wu, A. Toffanin, J. P. Shapleigh and H. D. Abruna. 1960. Electrocatalytic reduction of nitric oxide at electrodes modified with electropolymerized films of $[\mathrm{Cr}(\mathrm{v}-\mathrm{tpy}) 2] 3+$ and their application to cellular NO determination. Analytical Chemiatry 68: $3128-3134$.

Nicholson, R.S. and I. Shain. 1964. Theory of Stationary Electrode Polarography for a Chemical Reaction Coupled between Two Charge Transfers, Anal. Chem. 36: 706-723.

Rahman, K. L., M. A. Mamun and M.Q. Ehsan. 2011. Preparation of Metal Niacin Complexes and Characterization using Spectroscopic and Electrochemical Techniques. Russian J. Inorganic Chem. 56(9): 1436-1442.

Wang, J., J. Park, X. Wei, and C., Lee. 2003. Room-temperature heterogeneous hydroxylation of phenol with hydrogen peroxide over $\mathrm{Fe}^{2+}, \mathrm{Co}^{2+}$ ion-exchanged $\mathrm{Na} \beta$ zeolite. Chem. Commun. 2003: 628 .

Wopshall, R. H. and I. Shain. 1967. Effect of adsorption of electroactive species in stationary electrode polarography. Anal. Chem. 39: 1514-1527.

Xie, T., Q. Liu, and Y. A. Shi. 2006. Simultaneous determination of positional isomers of benzenediols by capillary zone electrophoresis with square wave amperometric detection. $J$. Chromatogr 1109: 317.

Zhang, J. and F. C. Anson. 1992. Voltametry and insitu FTIR spectroscopy of two anthraquinone disulfonates adsorbed on graphite electrode. J. Electranalytical Chem. 331: 945-957. 